\title{
Nanduty
}

\section{Apresentação dossiê - DIÁLOGOS EM TORNO DA BIOPOLÍTICA FOUCAULTIANA: CRUZANDO TEMAS, PROBLEMAS E PERSPECTIVAS}

O tema escolhido era portanto a "biopolitica": eu entendia por isso a maneira como se procurou, desde o século XVIII, racionalizar os problemas postos à prática governamental pelos fenômenos próprios de um conjunto de viventes constituídos em população: saúde, higiene, natalidade, longevidade, raças... (...). (Michel Foucault, In: Nascimento da biopolítica, 2008, p. 431)

O presente dossiê é fruto de um conjunto de discussões e reflexões realizadas ao longo de 2018 na disciplina Tópicos Especiais: "LEITURAS SOBRE BIOPOLÍTICA" ministrada junto ao Programa de Pós-Graduação em Antropologia Social da Universidade Federal do Rio Grande do Sul (PPGAS/UFRGS) por ambxs xs organizadorxs.

Naquele momento estávamos interessadxs em compreender como a categoria biopolítica se constituiu ao longo da trajetória filosófica de Michel Foucault, sua importância teórico-analítica, bem como alguns de seus desdobramentos contemporâneos - tanto para pensar suas possibilidades quanto seus limites (Nikolas Rose \& Paul Rabinow, 2006; Gilles Deleuze, 2013; Giorgio Agamben, 2002; Roberto Espósito, 2010; Judith Butler, 2017).

Mas qual a novidade inaugurada por Foucault em torno da noção de biopolítica? Por que um conceito constituído ao longo da segunda metade do século XX ainda se mostra tão operativo? Vale lembrar que é a conferência proferida por Foucault na UERJ em 1974 intitulada "O nascimento da medicina social" que o autor inaugura a discussão sobre a biopolítica ${ }^{1}$. Contudo, é a partir de 1976 que ele se debruçará sobre ela de forma sistemática. Destaque para as obras "Em Defesa da Sociedade" de 1976 - a aula de 17 de março - , "A Vontade de Saber" - do mesmo ano, "Segurança, Território e População" de 1978 e "Nascimento da biopolítica" de 1979. Em todas elas, a explicitação da emergência de um conjunto de mecanismos e procedimentos de saberpoder (estratégias) que teria como alvo o governo da população:

primeiro, o Estado de justiça, nascido numa territorialidade de tipo feudal, que corresponderia grosso modo a uma sociedade da lei - leis consuetudinárias e leis escritas -, com todo um jogo de compromissos e litígios; depois, o Estado administrativo, nascido numa territorialidade de tipo fronteiriça, e não mais feudal, nos séculos XV e XVI, esse Estado administrativo que corresponde a uma sociedade

\footnotetext{
${ }^{1}$ Nas palavras do autor, "O corpo é uma realidade biopolítica. A medicina é uma estratégia biopolítica" (In: Microfísica do Poder, 2007, p. 80)
} 


\section{Ñanduty}

de regulamentos e de disciplinas; e, por fim, um Estado de governo que já não é essencialmente definido por sua territorialidade, pela superfície ocupada, mas por uma massa: a massa da população, com seu volume, sua densidade, com, é claro, o território no qual ela se estende mas que de certo modo não é mais que um componente seu. (FOUCAULT In: Segurança, território, população 2008, p. 145).

Qual a marca desta "nova" configuração? Estava claro para Foucault que se no modelo de soberania prevalecia o "fazer morrer, deixar viver", no dispositivo biopolítico de gestão da vida impera o "fazer viver, deixar morrer". Portanto, de acordo com o autor, se o poder disciplinar estava pautado numa anátomo-política, tendo o corpo individual seu alvo por excelência, a biopolítica teria como foco principal o homem enquanto espécie. Nesse novo regime de saber-poder, todos os aspectos referentes à vida da população (processos de natalidade, de longevidade, de mortalidade, doenças, sexualidade, questões econômicas...) tornam-se problemas de governo. A grande questão passa a ser: Como organizá-los? Como conduzi-los? Como governá-los?

Desta forma acreditamos que os diferentes artigos aqui reunidos, a partir de campos disciplinares, problemas de pesquisa e métodos distintos, ao se proporem (direta ou indiretamente) uma (re)leitura do pensamento biopolítico foucaultiano, reafirmam a importância e atualidade epistêmica e política do tema/conceito. Para fins didáticos, optamos por distribuir os artigos em três grandes eixos temáticos: biopolítica e práticas de/em saúde; biopolítica e Estado; biopolítica, arte e educação.

Em relação ao primeiro eixo, Santiago Manuel Romero, a partir da realidade de Córdoba/Argentina, reflete sobre a produção social do suicídio como um problema governamental. Tatiane Pereira Muniz, por sua vez, ao voltar-se para o campo da biomedicina (a partir de seus diálogos com geneticistas) lança nova luz sobre as discussões raciais e seus dilemas biopolíticos. Já Renata Lemes Allram \& Gabriela Felten da Maia, a partir da categoria "zonas de abandono social", nos oportunizam pensar os dilemas que cercam as políticas assistenciais contemporâneas.

No que tange ao segundo eixo, os trabalhos de Jorge Helius Scola Gomes e de Vinícius Teixeira Pinto, respectivamente sobre a "Lei antiterrorismo" e sobre o fenômeno da "arenização" dos estádios de futebol, nos confrontam com as intricadas tramas biopolíticas que cercam as práticas de governo no Brasil atual. Érika de Freitas Arvelos \& David Silva de Oliveira, ao tomarem como cenário o pleito de 2018 no 


\section{Nanduty}

ISSN:2317-8590

Brasil, refletem sobre o que chamam de "o prólogo da bárbarie". Elizete Bernardes \& Solange Christiane Gonzalez Barros, por seu turno, a partir do assassinato de Marielle Franco, indagam "como o medo pode ser instalado como uma estratégia de governo biopolítico direcionado para corpos de determinados sujeitos?”. Em relação ao ódio a minorias, os respectivos artigos de Aguinaldo Rodrigues Gomes e de João Victor Rossi \& Simone Becker são provocativos. Gomes, a partir do conceito de "falocracia", reflete sobre as engrenagens que sustentam o machismo, a misoginia e a lgbtfobia na sociedade brasileira. Por sua vez, Rossi \& Becker, em diálogo com as reflexões necropolíticas de Mbembe, analisam as violências que são perpetradas contra corpos/expressões do feminino em Mato Grosso do Sul (MS).

Por fim, na interface biopolítica, arte e educação, Dayana Oliveira Arruda, Antônio Carlos do Nascimento Osório \& Carlos Igor Oliveira Jitsumori, ao tomarem como pano de fundo a Educação de Jovens e Adultos (EJA), trazem para a primeira cena a reflexão em torno dos discursos e práticas pedagógicas como jogos de verdade. No que tange a arte, Kesley Gabriel Bezerra Coutinho \& Márcio Alessandro Neman do Nascimento problematizam as estratégias de poder presentes na produção do mangá.

Na sessão resenhas Daniella Chagas Mesquita apresenta o livro "Gênero, sexualidade e saúde: Diálogos latino-americanos" organizado por Camilo Braz e Carlos Eduardo Henning. Por sua vez, Ana Lígia Saab Vitta \& Júlia Arruda da Fonseca Palmiere nos brindam com a análise do livro "Corpos em aliança e a política das ruas: notas para uma teoria performativa da assembleia", de Judith Butler.

Convidamos ainda xs leitorxs a prestigiarem o artigo de Yan Leite Chaparro, Joaquim Adiala Hara \& Josemar de Campos Maciel, que inaugura a sessão "Ensaios Bibliográficos" aqui na Revista Ñanduty. Esperamos, a partir de agora, que esse espaço possa oportunizar a estudantes e pesquisadorxs indígenas, quilombolas, LGBTs a socialização de suas reflexões e insights.

Por fim, agradecemos a todxs xs pesquisadorxs que aceitaram nosso convitedesafio e esperamos que xs leitorxs possam se deliciar com as saborosas e provocativas discussões biopolíticas aqui travadas.

Xs organizadorxs. 